\title{
To friend, or not to friend, that is the question ... or is it?
}

I am a digital immigrant. ${ }^{1}$ Unlike my avoidant (older) colleagues, I am insecurely enthusiastic about interacting with my patients using social media, where over $60 \%$ of my patients reside. ${ }^{2}$ My patients are digital natives, ${ }^{1}$ securely attached to technological gadgets and gizmos, unaware of a world without such devices. Many of them can text and tweet before they can ride a bike. Their social and emotional development is closely entwined with virtual interactions.

So why is it then, when I receive a "friend request" from a patient, my internal alarm sounds off? Part of me perceives this as a violation of personal space. But, a part of me is also honoured that he or she scoured through millions of profiles to find the real me, their doctor, their friend. I am also curious about the origin and intention of this request. Did this patient mistake our therapeutic relationship as a friendship? How could I have possibly led him or her down this twisted path?

Perhaps it's my fault. As a pediatrician, I commonly use terms of endearment in my professional vernacular, like "little buddy" or "sweetie" or "sport" or "pal." Certainly most of these terms don't belong in professional interactions with adults, but when dealing with kids it would be equally awkward to address them as Ms. Banerjee or Mr. Smithson. We use formal titles to provide a notion of respect and professionalism for our adult patients. But, the terms we use in pediatrics are more informal. Do my patients assume this informality has deeper meaning, that they are indeed my friend?

If I were really their friend, then they would expect me to empathetically listen to their stories, help them get through rough times and entrust me with their secrets. Wait, this is what my patients expect of me. Perhaps, in this world of fragmented and depersonalized medicine, this "friend request" is an attempt to form a deeper, meaningful connection with their physician; an

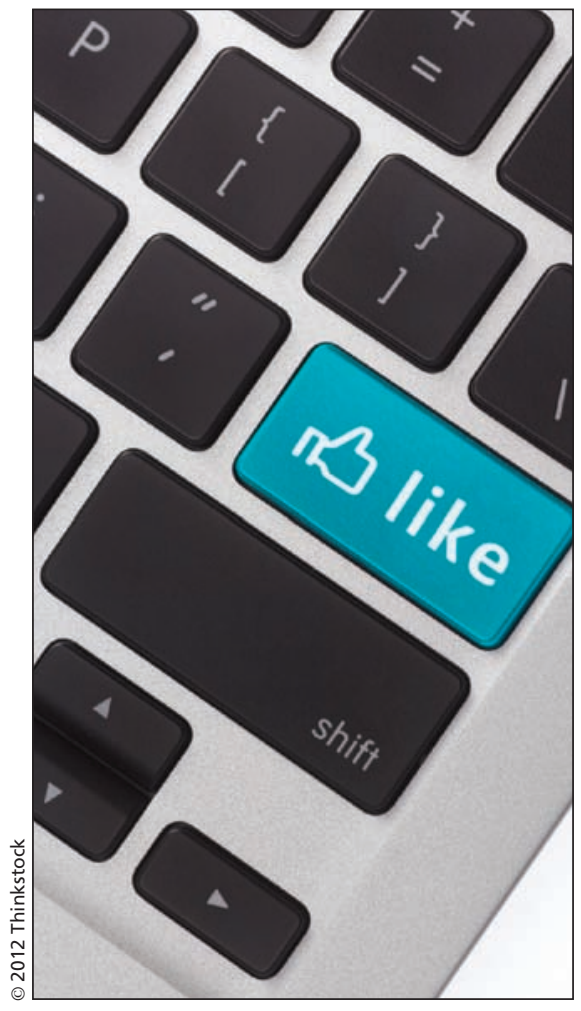

attempt to humanize us and treat us as equals. After all, long gone are the days of paternalistic medicine, when physicians were ordained as guardians of the sacred medical testaments and patients were only privy to information from their physicians. The Internet removes all information imbalances. As such, the role of the physician is changing from an information custodian to that of a medical interpreter and deliberative coach. Along with information equality comes an ever-increasing expectation for individual and institutional transparency. 3,4 Thus, perhaps this "friend request" is a reflection of my contemporary consumer's tech-savviness and expectation for me to be present in their world, as they are in mine.

In "their world," patients and other inhabitants of Generation Z connect with each other through social media, at the cost of confidentiality. In "their world," audience and author are equal and can shift fluidly from one role to another, building connections and com- munities around shared interests and illness. Although "their world" may be foreign and uncomfortable to many of us, for them it is a safe place to seek out information, ask questions and engage with friends and physicians alike. In "their world," there is immense opportunity for me to appreciate my patients' needs, values, preferences and beliefs as their online "friend." So, maybe it is possible to be friendly with my patients, and have patients as online "friends."

In today's digital landscape, I can no longer plead technological ignorance. My patients live in the world of social media and I need a passport to cross this digital divide. But when I enter this world, I will apply for dual citizenship. Like in the "real world," I will preserve my online integrity by having both personal and professional identities. However, unlike a superhero, my civilian and secret identities will coexist to keep my intentions clear and honest. The use of social media has become transparent, like other utilities of daily use. My patients post, poke, tag and tweet as their preferred languages in which to converse, and it's time for me to get a translator.

\section{Niraj Mistry BSc MD}

Academic General Pediatric Fellow The Hospital for Sick Children Toronto, Ont.

\section{Rosanna Macri MRT(T), MHSc}

Bioethicist

Ontario Shores Centre for Mental

Health Sciences

Whitby, Ont.

\section{References}

1. Pensky M. Digital natives, digital immigrants: a new way to look at ourselves and our kids. On the hori zon 2001;9:1-6. Available: www.marcprensky.com /writing/Prensky\%20-\%20Digital\%20Natives, \%20 Digital\%20Immigrants\%20-\%20Part1.pdf (accessed 2012 May 29)

2. Fox S. Health topics. Washington (DC): Pew Internet and American Life Project; 2011. Available www.pewinternet.org/ /media//Files/Reports/2011 /PIP_HealthTopics.pdf (accessed 2012 May 29).

3. Mackay B. RateMDs.com nets ire of Canadian physicians. CMAJ 2007; 176:754

4. Vogel L. The road map to better hospitals. CMAJ 2012;184:E399-400.

CMAJ 2012. DOI:10.1503/cmaj.120838

All editorial matter in CMAJ represents the opinions of the authors and not necessarily those of the Canadian Medical Association. 